\title{
Urgences
}

\section{Couvent de ville (1965)}

\section{Jean Deschamps}

Numéro 4, 2e trimestre 1982

URI : https://id.erudit.org/iderudit/025055ar

DOI : https://doi.org/10.7202/025055ar

Aller au sommaire du numéro

Éditeur(s)

Urgences

ISSN

0226-9554 (imprimé)

1927-3924 (numérique)

Découvrir la revue

Citer ce document

Deschamps, J. (1982). Couvent de ville (1965). Urgences, (4), 19-22.

https://doi.org/10.7202/025055ar

Ce document est protégé par la loi sur le droit d'auteur. L'utilisation des services d'Érudit (y compris la reproduction) est assujettie à sa politique d'utilisation que vous pouvez consulter en ligne.

https://apropos.erudit.org/fr/usagers/politique-dutilisation/
Cet article est diffusé et préservé par Érudit.

Érudit est un consortium interuniversitaire sans but lucratif composé de l'Université de Montréal, l'Université Laval et l'Université du Québec à Montréal. Il a pour mission la promotion et la valorisation de la recherche. https://www.erudit.org/fr/ 
JEAN DESCHAMPS

\section{Couvent de ville}

(1965) 
Par paliers successifs I'intérieur se dilate. C'est une pluie de sel intra-veineuse. Somme de picotements. Un geste de la main qu'on vient d'arrêter et qui, pourtant, semble continuer dans l'espace. Jonction de détails jusqu'alors inaperçus. La lucidité se débarrasse du paraître. Les muscles faciaux révèlent comment ils sont instigateurs de mimiques. Sous les paupières, des oscillations provenant ni des yeux ni de l'artère temporale. Un court balancement entre faits plausibles et l'explosion des possibles.

- Tu es mort, verraine... - On a pas le droit dans les jambes, crime de stick... - C'est pas là que j'ai tiré. Tu es mort pareil, le saff... - Tu sauras que je suis pas un saff, gros nez... - C'est toujours moi qui compte! Puis, mon hostine, tu as besoin de dire à ta soeur qu'elle vienne quand on jouera a la bouteille... - Tu sauras que ma soeur, (il crache au sol) elle peut choisir ses kiks toute seule...

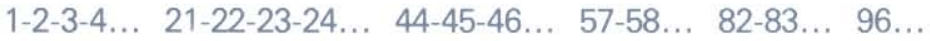
100 ! - Prêt, pas prêt, j'y vais!

$-1,2,3$ pour la boule.. je t'ai vu!... - Je vais t'en faire, tu m'as vu... Premièrement, j'ai même pas tiré... Tu vas voir, mon smatte, m'a t'en étamper une!... - Calvinsse, Bouboule, les nerfs!... - T'es rien qu'un tricheur... - Toi aussi, cream puff... l'autre jour, tu voulais même pas avoir la taillgue... - C'était pas à moi la taillgue... - Ah non? C'était à qui d'abord?... - Laisse faire, gros nez, m'a te péter la fiouze, tu vas voir!... - Arrête de m'achaler, tapette... - Eh ben, si c'est comme ça, gâdemm, je joue plus pantoute.. - Eille, toi le lâche, $t^{\prime}$ as besoin de te r'niper, sans ça tu manges une beurrée... - Je retourne au couvent, bande de colons!

- Vous devez tous lire: HYGIĖNE ET BIENSĖANCE... Oui, ma Soeur... - Encore une chose... Dans la cour, il y a un 
côté pour les filles et un côté pour les garçons... - Oui, ma Soeur... - Quant à toi, ce soir, c'est la retenue. Plus d'une fois tu as sauté la clôture pour aller dans la cour des filles!... - Non, ma Soeur... - Comment?... - Euh... ma... oui ma Soeur... - Il faudra copier Le Guide de l'Étudiant modèle en changeant le crayon de couleur à chaque ligne!... - Mais, ma Soeur... - Et sans vo-ci-fé-ra-tion!... - Sans quoi?... - Allez, allez... marche!... - Oui, ma Soeur.

Eh! Boule, as-tu vu Simone? La Soeur m'a fait copier à cause d'elle... - Elle est en arrière, là-bas... - Simone!... Siiiimone!... Qu'est-ce que tu fais?... - Je joue à qui s'ki la, c'est Marie-Stella!... - J'aì mangé une retenue à cause de toi, j'y vais pas à midi... - Tans pis, j'ai une cocotte, tu l'auras pas, c'est toutte.

- Tu es bon toi, Lorin, au ballon pied, serais-tu capable de débarquer la capine de la Soeur avec un bon kik en ligne droite?... - Es-tu fou?... - On va enfin savoir si ses cheveux sont en brosse en dessous... - Ciboulette d'hostinsse, elle va me tuer!... - C'est pas grave, viande, elle va quand même t'accrocher, Swanson lui a dit que tu flanquais ton dîner entre les roches de la cour d'école... - Sainte-Appoline!... J'suis fini, simonac!... Où il est le stool à Swanson?... - II tire du slingshot à l'autre bout... - Eh, Swanson... Swannnnnnson... vieille police numéro trente-six qui mange des saucisses à midi moins dix!

- Tu me dois deux billes, la Boule!... - Es-tu trop pissou pour faire quitte ou double?... - Moi pissou? Je m'étouffe pas comme toi quand je respire une cig... - Envoye, joue!... Pi bon, si je pique le tabarslaque d'enfant d'chique à Swanson... - La dernière fois, oublie pas, $t^{\prime}$ en a mangé toute une!... - II avait une roche dans sa mitaine, I'enfant de nanane!... - Dégnaise, tapette de gnaise!... - Traite moi pas de tapette, la Boule, sans ça... - Envoye, joue!

- Les gars, est-ce qu'on va dans la cour des filles, à soir? Simone a montré son vaccin qui gratte dans le dos... On a vu ses collants! 
(Soeur Amanda m'a fait copier Le Guide de l'Étudiant modèle avec un système de crayons à couleurs écoeurantes)... - Je vais glisser en traîneau, gang... $-\ldots-$ Simone? Simone!... - Ah! ben y'é temps que tu arrives, toi... - C'est que, tu vois, Bouboule me devait deux billes. On a joué quitte ou double. Après, on a joué pareil pas pareil, quitte ou triple avec les doigts... (Torpinouche, je me sacre bien des billes à la Boule!)... Wa ta tor, Simone! Me v'là, sacrifice!... 